\title{
Activated Carbon Prepared from Corn Biomass by Chemical Activation with Potassium Hydroxide
}

\author{
Beata Doczekalska, Monika Bartkowiak, Hubert Łopatka, and Magdalena Zborowska * \\ With the depletion of fossil fuel feedstocks, the lignocellulosic biomass, \\ including the agro-wastes, can serve as the best alternative source to \\ produce activated carbons (ACs). Corn biomass (corn leaves, stalks, cobs \\ without kernels, silk, and kernels) were used to produce ACs in a two-step \\ process. Crushed plant material was carbonized at $600{ }^{\circ} \mathrm{C}$ and then the \\ obtained carbon was activated using potassium hydroxide at $750^{\circ} \mathrm{C}$. The \\ content and type of surface oxygen functional groups were determined by \\ the Boehm method and infrared spectroscopy. The porous structure of the \\ obtained AC was determined by the nitrogen adsorption/desorption \\ method at $-196{ }^{\circ} \mathrm{C}$, and the thermal resistance by the thermogravimetric \\ method. The iodine number was also determined. The ACs derived from \\ corn biomass were characterized with surfaces rich in chemical groups \\ and revealed a highly developed porous structure. The specific BET \\ surface area ranged from $1600 \mathrm{~m}^{2} / \mathrm{g}$ to $1965 \mathrm{~m}^{2} / \mathrm{g}$. High values of iodine \\ number approx. $1300 \mathrm{mg} / \mathrm{g}$, indicated an extensive system of pores and \\ their good adsorption properties.
}

DOI: 10.15376/biores.17.1.1794-1804

Keywords: Activated carbon; Corn biomass; Chemical activation; Pore structure

Contact information: Poznań University of Life Sciences, Department of Chemical Wood Technology, ul. Wojska Polskiego 38/42, 60-637 Poznań, Poland;

* Corresponding author: magdalena.zborowska@up.poznan.pl

\section{INTRODUCTION}

Carbon materials have been used by humans since the dawn of time. The first reports of the use of activated carbons (ACs) date back to $1500 \mathrm{BC}$, where an Egyptian papyrus describes the treatment of rotting wounds with charcoal to remove the unpleasant odor of decaying tissue. Hippocrates and his students used charcoal as a medicine for many diseases. Also, Pliny the Elder, in his work on Natural History, presented coal as a remedy for many ailments, including epilepsy, anemia, and dizziness. Africans and Aborigines, on the other hand, still use charcoal as a poultice to draw poison from wounds inflicted by poisonous animals, including spiders, snakes, scorpions, and others. The Indians, on the other hand, use charcoal to heal burns caused by poison ivy. Currently, AC is used as a remedy for diarrhea and poisoning. On an industrial scale, AC was produced in the first half of the 19th century for the purification of sugar (Bansal and Goyal 2005). At the beginning of the $20^{\text {th }}$ century, activation methods using steam (Ostreijko) or chemical activation (Bayer) methods began to be widely used. During World War I, carbon obtained from coconut shells was used in gas masks. After World War II, the Calgon Corporation USA developed granulated ACs (Dąbrowski 1999).

Activated carbons are currently used in many industries. In recent years, there has been a very rapid increase in both the scale and the range of their various applications. 
They are well suited as adsorbents and as catalysts or catalyst carriers (Narowska et al. 2019; Abd et al. 2021). Because of its ability to store energy, the AC is also used in electrochemistry, e.g., for the construction of capacitors and batteries (Betzy and Soney 2015; Kolonowski et al. 2020). The wide use of ACs is owing to their unique porous structure and highly developed specific surface area up to $2000 \mathrm{~m}^{2} / \mathrm{g}$, and the specific chemical structure of their surface.

Currently, the main raw materials used to produce ACs include hard and brown coal, peat, wood, and coconut shells. Obtaining carbon material from non-renewable sources is associated with a negative impact on the environment. In the age of ecology, more and more stringent environmental protection regulations force us to look for new, safe raw materials (precursors) to produce AC.

Great emphasis is placed on the use of lignocellulosic materials, waste from forestry, and agricultural production as well as agri-food production (Danish and Ahmad 2018; Gonzalez-Garcia 2018; Doczekalska et al. 2020; Panwar and Pawar 2020). The production of ACs from lignocellulosic biomass has many advantages. Such precursors are diverse, readily available and renewable, cheap, and biocompatible with the natural environment. Moreover, the production of AC from them is a relatively simple process due to the high reactivity of the biomass.

In this study, various anatomical parts of maize were used as precursors. So far, only studies on the preparation of $\mathrm{AC}$ from corn cobs have been described in the literature (Aggarwal and Dollimore 1997; Bagheri and Abedi 2009; Kaźmierczak et al. 2013; Li et al. 2018; Liu et al. 2020; Iheanacho et al. 2021). Corn (Zea mays L.) is one of the staple foods of carbohydrate source substitute for rice. The use of corn has increased tremendously, which causes environmental problems because merely the seeds are used as food while corn cobs and cornstalk waste are discarded and burned. The effort of applying the corn cobs waste as economic material for making activated carbon are beneficial. The structural content of corn cob i.e., cellulose (41\%), hemicellulose (36\%), and lignin (6\%) indicating that corn cob can be potentially and effectively used as a precursor for AC making, besides that the ash content contained in corn cobs is also quite low at 1.50\% (Kulp and Ponte 2000). The corn cobs with the high carbon content of $80.5 \%$ and low ash content is also an advantage from the other biomass for AC production.

The aim of the study was to obtain and test the properties of ACs from various anatomical parts of maize, i.e., corn kernels, corn silk, corn stalks, corn leaves, and corn cobs without kernels. Potassium hydroxide $(\mathrm{KOH})$ was used as a chemical activator. The properties of the obtained products were evaluated via the content of surface oxygen functional groups, parameters of the porous structure, iodine number, and thermal resistance.

\section{EXPERIMENTAL}

\section{Materials}

The raw material for AC production was common maize (Zea mays L.), Legion C1, F1 variety. It was collected in the Wielkopolska-Pomeranian region, Śrem poviat, at its full maturity. Anatomical plant parts were separated from the dried plants (Fig. 1), i.e., corn kernels, corn silk, corn stalks, corn leaves, and corn cobs without kernels which were then crushed into 10-20 mm fractions. The raw materials were stored at a temperature of $20 \pm 2$ ${ }^{\circ} \mathrm{C}$, with an $\mathrm{RH}$ of $60 \pm 5 \%$. The following symbols were used to mark the AC samples 
obtained from the maize part: AC-K - corn kernels, AC-CS - corn silk, AC-S - corn stalks, AC-L - corn leaves, and AC-C - corn cobs without kernels.

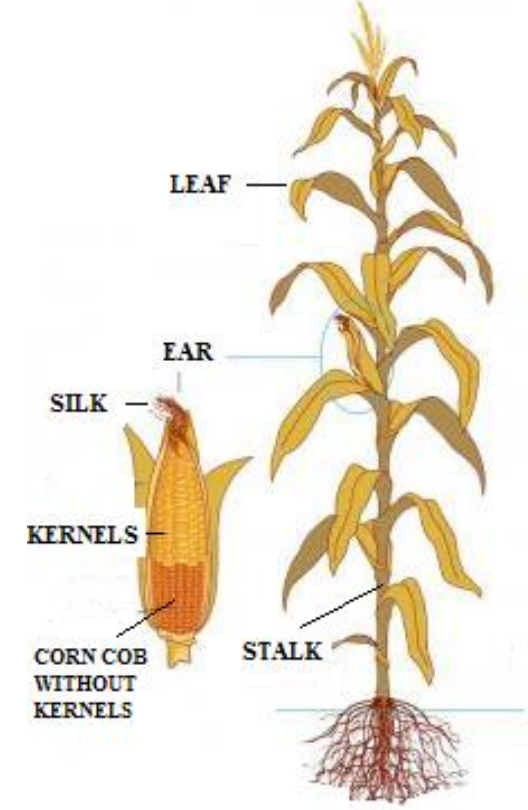

Fig. 1. Parts of corn plants used to obtain activated carbons

\section{Preparation of Activated Carbon}

Activated carbons were obtained from various plant parts of corn biomass. Lignocellulosic materials were first subjected to pyrolysis and carbonization in oxygenfree atmosphere by heating to $600{ }^{\circ} \mathrm{C}$ at the rate of $3{ }^{\circ} \mathrm{C} / \mathrm{min}$ and then, holding in stable conditions for $1 \mathrm{~h}$. The carbonized samples after grinding were activated with $\mathrm{KOH}$ at mass ratio of 1:4 in argon atmosphere at a temperature of $750{ }^{\circ} \mathrm{C}$ for $15 \mathrm{~min}$ in a nonporous ceramic reactor. The ACs were washed with $2 \%$ hydrochloric acid followed by deionized water to the neutral $\mathrm{pH}$. Prior to use, the ACs were dried in an oven at $105{ }^{\circ} \mathrm{C}$ to a constant weight and stored in a desiccator for further study.

\section{Determination of Active Carbon Properties}

Surface oxygen groups

This property was determined following Boehm's method (Boehm 1994). Approximately $0.25 \mathrm{~g}$ of each AC sample was placed in a $250 \mathrm{~mL}$ flask. After adding 25 $\mathrm{mL}$ of $0.1 \mathrm{~mol} / \mathrm{L}$ solution of $\mathrm{NaOH}, \mathrm{NaHCO}_{3}$, and $0.05 \mathrm{~mol} / \mathrm{L}$ solution of $\mathrm{Na}_{2} \mathrm{CO}_{3}$ (for determination of acidic groups) or $0.1 \mathrm{~mol} / \mathrm{L} \mathrm{HCl}$ (for determination of basic groups), the mixtures were shaken for $24 \mathrm{~h}$. After filtering the mixtures, $10 \mathrm{~mL}$ of each filtrate was pipetted and the excess of base and acid was titrated (Tashiro indicator) using $0.1 \mathrm{~mol} / \mathrm{L}$ solution of $\mathrm{HCl}$ or $\mathrm{NaOH}$, respectively. All experiments were repeated twice. The numbers of acidic sites of various types were calculated under the assumption that $\mathrm{NaOH}$ neutralizes carboxyl, phenolic, and lactonic groups $\left(\mathrm{Na}_{2} \mathrm{CO}_{3}\right.$ - carboxyl and lactonic; and $\mathrm{NaHCO}_{3}$ only carboxyl groups). The number of surface basic sites was calculated from the amount of $\mathrm{HCl}$ that reacted with carbon.

Fourier transform-infrared spectra (FTIR)

The AC samples were analyzed on an Alfa FTIR spectrometer (Bruker Optics $\mathrm{GmbH}$, Karlsruhe, Germany) by KBr pellets. The spectra were acquired by accumulating 
24 scans at a resolution of $4 \mathrm{~cm}^{-1}$ in absorbance mode in the wavenumber range from 4000 to $700 \mathrm{~cm}^{-1}$.

\section{Parameters of the porous structure}

The pore parameters of AC were determined from nitrogen sorption isotherms at $-196{ }^{\circ} \mathrm{C}$ (Micromeritics ASAP 2020, Norcross, GA, USA). Samples before measurement were degassed at $300{ }^{\circ} \mathrm{C}$ for $10 \mathrm{~h}$ at pressure $1 \times 10^{-6} \mathrm{~Pa}$. Collected sorption data made it possible to calculate the following structural parameters in the area of micro- and mesopores:

- $\quad$ BEt - specific surface area by BET (Brunauer, Emmett and Teller) method - to the relative pressure $p / p_{0} \approx 0.2$,

- $\quad V_{\text {total }}$ - a total pore volume determined from the isotherm at a relative pressure $p / p_{0} \approx 0.975$,

- $\quad V_{\text {meso }}$ - mesopores volume by BJH method,

- $\quad V_{\text {micro }}$ - micropores volume by t-plot method,

- $d_{\text {average }}$ - average pore diameter calculated from formula $d_{\text {average }}=4 V_{\text {total }} / S_{\text {BET }}$.

\section{Iodine numbers (IN)}

Iodine numbers of ACs were determined based on the ASTM-D4607-94 standard method. Thus, the IN ( $\mathrm{mg} \mathrm{I}_{2} / \mathrm{g}$ carbon) was measured by titration at $30{ }^{\circ} \mathrm{C}$. From each $\mathrm{AC}$ sample, three dried samples $(0.1 \mathrm{~g}$ each $)$ were placed into separate flasks and fully wetted with $10 \mathrm{~mL}$ of $5 \% \mathrm{HCl}$. Then $100 \mathrm{~mL}$ of $0.025 \mathrm{M}$ standard iodine solution was added into the flask and the content was vigorously shaken for $30 \mathrm{~s}$. After quick filtration, $50 \mathrm{~mL}$ of the solution was titrated using $0.1 \mathrm{M}$ sodium thiosulfate using starch as an indicator. The concentration of iodine in the solution was calculated according to Eq. 1 from the total volume of sodium thiosulfate used,

$$
\text { IN }=\frac{\left(V_{0}-V_{x}\right) \times c_{\text {thio }} \times 126.92}{m}\left[\frac{m g}{g}\right]
$$

where $V_{0}$ and $V_{\mathrm{x}}$ are the volumes of sodium thiosulfate solution used for titration of assayed $\left(V_{\mathrm{x}}\right)$ and blank samples $\left(V_{0}\right)[\mathrm{mL}]$; $c_{\text {thio }}$ is the concentration of sodium thiosulfate solution $[\mathrm{M}] ; m$ is the mass of activated carbon sample [g]; and 126.92 is the mass of 1 mole of iodine $[\mathrm{g}]$.

\section{Thermogravimetric analysis (TG)}

The analysis was carried out on STA 449 F5 Jupiter-QMS of the NETZSCH (MA, USA) using the following conditions: final temperature $1200{ }^{\circ} \mathrm{C}$, temperature increase at $5^{\circ} \mathrm{C} / \mathrm{min}$, and helium flowing at the rate of about $25 \mathrm{~mL} / \mathrm{min}$. The weight of the sample used was $10 \mathrm{mg} \pm 1 \mathrm{mg}$.

\section{RESULTS AND DISCUSSION}

The porous structure of ACs, and thus their adsorption capacity, is largely determined by the properties of the starting material and the conditions used for its preparation, such as carbonization parameters (i.e., end temperature, cooling method and rate, temperature raising rate, and atmosphere) and the type of the factors used in the activation process. 
Table 1 summarizes different preparation methods of corn cobs based ACs (AC-C sample) and their BET surface area $\left(S_{\mathrm{BET}}\right)$. Comparing the various methods used to obtain ACs from corn cobs, it can be stated that the specific surface area obtained by chemical methods was much larger than that obtained by physical methods. Based on these reports, in this work, the ACs were obtained by chemical activation method, and $\mathrm{KOH}$ was used as an activator.

Table 1. Comparison of ACs from Corn Cob with Different Activation Methods

\begin{tabular}{|c|c|c|}
\hline Preparation Method & BET Surface Area $\left(\mathrm{m}^{2} / \mathrm{g}\right)$ & Reference \\
\hline Chemical, $\mathrm{KOH}$ & 1682 & Tsai et al. 2001 \\
\hline Chemical, $\mathrm{KOH}$ & 1600 & Song et al. 2013 \\
\hline Chemical, $\mathrm{KOH}$ & 1320 & Bagheri and Abedi 2011 \\
\hline Chemical, $\mathrm{KOH}$ & 1054 & Liu et al. 2020 \\
\hline Chemical, $\mathrm{KOH}$ & 1884 & This study \\
\hline Chemical, $\mathrm{K}_{2} \mathrm{CO}_{3}$ & 1266 & Tsai et al. 2001 \\
\hline Chemical, $\mathrm{ZnCl} 2$ & 924.9 & Tang et al. 2016 \\
\hline Physical, Steam & 980 & Song et al. 2013 \\
\hline Physical, $\mathrm{Steam}$ & 630 & Ioannidou et al. 2010 \\
\hline Physical, $\mathrm{CO}_{2}$ & 431 & Milenković et al. 2013 \\
\hline Physical, $\mathrm{CO}_{2}$ & 143 & Nethaji et al. 2013 \\
\hline
\end{tabular}

The results from other reported studies (Lillo-Rodenas et al. 2003, Linares-Solano et al. 2008, Raymundo-Piñero et al. 2005) indicate that carbon hydroxide activation occurs through the reaction of Eq. 2.

$$
6 \mathrm{MOH}+2 \mathrm{C} \leftrightarrow 2 \mathrm{M}+3 \mathrm{H}_{2}+2 \mathrm{M}_{2} \mathrm{CO}_{3}
$$

(where $\mathrm{M}$ is $\mathrm{Na}$ or $\mathrm{K}$ )

This solid-liquid redox reaction transforms hydroxides, a result of oxidation of the carbon precursor, into the main products: hydrogen, alkali metals, and alkali carbonates. Often this reaction (Eq. 2) is carried out at a temperature range of $700{ }^{\circ} \mathrm{C}$ to $900{ }^{\circ} \mathrm{C}$.

Two types of functional groups determine the chemical structure of the surface of ACs (Bansal and Goyal 2005). Acidic functional groups such as carboxyl, phenolic, carbonyl, lactone, anhydride groups are very well characterized and give the carbon structure a hydrophilic and polar character. The structure of alkaline functional groups of pyronium type structure is not fully understood, but they are also classified as chromene structures. This structure has an oxygen-containing heterocyclic ring fused to an active group of $=\mathrm{CH}_{2}$ or $=\mathrm{CHR}$ ( where $\mathrm{R}$ is an alkyl group).

The presence and type of oxygen functional groups present on AC surface primarily determine the ion-exchange properties of AC. They also affect their adsorption, electrochemical, catalytic, redox, and hydrophobic-hydrophilic properties. The determination of the content of acidic and alkaline oxygen functional groups on the surface of AC was carried out using the Boehm method and is summarized in Table 2.

There was a substantial amount of surface oxygen groups on the surface of the ACs from corn biomass (Table 2). Activated carbons showed an acidic surface character. In the case of carbon material obtained from AC-L, the advantage of acidic groups over basic groups was small. The results of the determinations indicate that carboxyl groups provided the greatest share in acidity. The low content of lactone groups is most likely due to their inferior thermal resistance compared to phenolic and carboxyl groups (Szymański et al. 
2002). On the other hand, the highest number of phenolic groups was found in the case of carbon produced from AC-S.

Table 2. Surface Oxygen Functional Groups

\begin{tabular}{|c|c|c|c|c|c|}
\hline \multirow{3}{*}{ ACs } & \multicolumn{5}{|c|}{ Functional Groups (mmol/g) } \\
\hline & \multicolumn{3}{|c|}{ Acidic } & \multirow{2}{*}{$\begin{array}{l}\text { Acidic } \\
\text { (Total) }\end{array}$} & \multirow{2}{*}{$\begin{array}{l}\text { Basic } \\
\text { (Total) }\end{array}$} \\
\hline & Lactonic & Phenolic & Carboxylic & & \\
\hline $\mathrm{AC}-\mathrm{K}$ & 0.29 & 0.63 & 1.23 & 2.15 & 0.77 \\
\hline AC-CS & 0.30 & 0.62 & 1.33 & 2.25 & 0.48 \\
\hline AC-S & 0.20 & 0.77 & 1.26 & 2.23 & 0.53 \\
\hline$A C-L$ & 0.15 & 0.62 & 1.27 & 1.93 & 1.83 \\
\hline AC-C & 0.29 & 0.58 & 1.27 & 2.14 & 0.68 \\
\hline
\end{tabular}

AC samples obtained from the maize part: AC-K - corn kernels, AC-CS - corn silk, AC-S - corn stalks, AC-L - corn leaves, and AC-C - corn cobs without kernels

In the FTIR spectra of ACs (Fig. 2), the absorption bands at similar wavenumbers in the vibrational region of 4000 to $2000 \mathrm{~cm}^{-1}$ are visible. The most intense bands were apparent around 3430 to $3420 \mathrm{~cm}^{-1}$, and they come from the stretching vibrations of $-\mathrm{OH}$ groups in various configurations and also from chemisorbed water. The absorbance bands at $2920 \mathrm{~cm}^{-1}$ and $2850 \mathrm{~cm}^{-1}$ are characteristics of $-\mathrm{C}-\mathrm{H}$ stretching vibrations in aromatic and aliphatic structures and for the $-\mathrm{CH}_{3}$ and $-\mathrm{CH}_{2}$ groups. The peaks in the range 1740 to 1730 $\mathrm{cm}^{-1}$ on the carbon spectra can be attributed to the stretching vibrations of the $-\mathrm{C}=\mathrm{O}$ bonds from carboxyl, ester, and lactone groups.

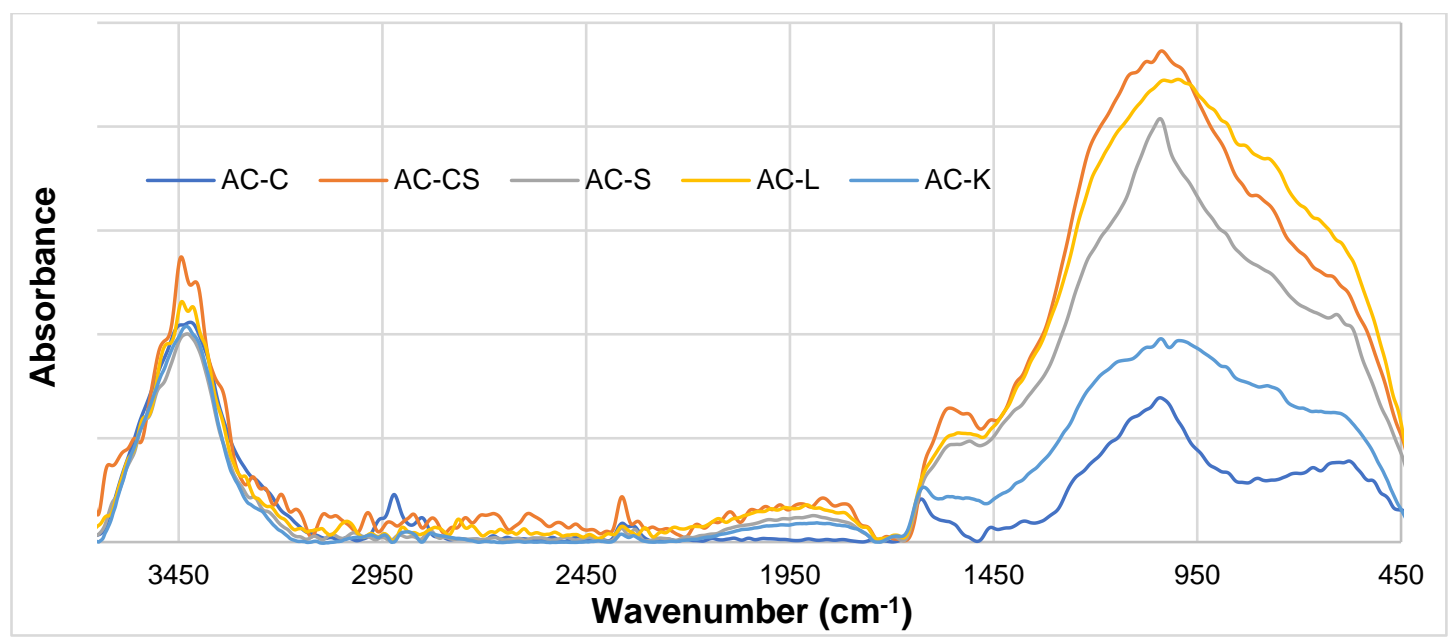

Fig. 2. Infrared spectra of activated carbon (see ACs abbreviations below Table 2)

Boehm's method showed the presence of carbonyl groups, which is confirmed by the presence of the band at the wavenumber of $1740 \mathrm{~cm}^{-1}$. Additionally, the spectrum of the carbon showed a band of vibrations at $1635 \mathrm{~cm}^{-1}$, corresponding to the stretching vibrations of $-\mathrm{C}=\mathrm{O}$ bond. On the other hand, the spectra show a band at $1558 \mathrm{~cm}^{-1}$, which arises from the $-\mathrm{C}=\mathrm{O}$ stretching vibrations of diketones, ketoesters, and ketoenol groups or the $-\mathrm{C}=\mathrm{C}$ stretching vibrations of aromatic rings (Biniak et al. 1997; Figueiredo et al. 1999; 
Pietrzak and Wachowska 2003; Pietrzak and Bandosz 2007). The similarity of the spectra was found in the case of corn kernels and corn cob without kernels. In their case, the absorbance was the lowest, and there was no evidence of any band below $1537 \mathrm{~cm}^{-1}$, which was present in the spectra of other ACs samples.

Results of the Boehm's method (Table 2) and FT-IR measurements made for the ACs are shown in Fig. 3. The table provides information about the functional groups formed on the material surface, which are very important for the evaluation of the adsorption properties.

Textural parameters are considered to have a strong influence on the adsorption efficiency of an AC sample. Hence, textural characterizations were performed (Table 3) to determine the surface area $\left(S_{\mathrm{BET}}\right)$ as well as the micropore $\left(V_{\text {micro }}\right)$ and mesopore $\left(V_{\text {meso }}\right)$ volumes of the adsorbents. The nitrogen adsorption-desorption isotherms are presented in Fig. 3.

Table 3. Characteristic of the Porous Structure of the Activated Carbon

\begin{tabular}{|c|c|c|c|c|c|c|c|}
\hline ACs & $\begin{array}{c}\text { Surface Area } \\
\left(\mathrm{m}^{2} / \mathrm{g}\right)\end{array}$ & \multicolumn{3}{|c|}{$\begin{array}{c}\text { Pore Volume } \\
\left(\mathrm{cm}^{3} / \mathrm{g}\right)\end{array}$} & $V_{\text {micro }} / V_{\text {total }}$ & $\begin{array}{c}\text { Pore Width } \\
(\mathrm{nm})\end{array}$ & $\begin{array}{c}\text { lodine Number } \\
(\mathrm{mg} / \mathrm{g})\end{array}$ \\
\hline & $S_{\mathrm{BET}}$ & $V_{\mathrm{T}}$ & $V_{\text {micro }}$ & $V_{\text {meso }}$ & & $d_{\text {average }}$ & $I \mathrm{~N}$ \\
\hline AC-K & 1965 & 1.12 & 0.32 & 0.80 & 0.29 & 2.28 & 1280 \\
\hline AC-CS & 1600 & 1.15 & 0.53 & 0.62 & 0.46 & 2.88 & 1290 \\
\hline AC-S & 1948 & 1.27 & 0.33 & 0.94 & 0.26 & 2.61 & 1290 \\
\hline AC-L & 1721 & 1.30 & 0.67 & 0.63 & 0.51 & 3.02 & 1280 \\
\hline AC-C & 1884 & 1.19 & 0.31 & 0.88 & 0.26 & 2.53 & 1310 \\
\hline
\end{tabular}

Note: See ACs abbreviations below Table 2.

For almost all isotherms (Fig. 3), quite high adsorption values can be found in the range of low relative pressures (up to 0.1 ), i.e., about $500 \mathrm{~cm}^{3} / \mathrm{g}$. This may indicate the presence of a micropore system. These curves are also characterized by steep courses in the range of relative pressures from 0.1 to 0.4 , in which nitrogen is absorbed mainly in the mesopores. High adsorption values (over $800 \mathrm{~cm}^{3} / \mathrm{g}$ ) are characteristic of carbons obtained from corn stalks (AC-S) and leaves (AC-L).

All the obtained activated carbons were characterized by a high specific surface area, i.e., from $1721 \mathrm{~m}^{2} / \mathrm{g}$ to $1965 \mathrm{~m}^{2} / \mathrm{g}$, and a high total pore volume between $1.12 \mathrm{~cm}^{3} / \mathrm{g}$ and $1.30 \mathrm{~cm}^{3} / \mathrm{g}$. The largest $S_{\mathrm{BET}}$ areas were obtained by using corn kernels and stalks as precursors. Surface area $\left(\mathrm{S}_{\mathrm{BET}}\right)$ values increased in the order: AC-CS $<$ AC-L $<$ AC-C $<$ AC-S $<$ AC-K. The $V_{\text {micro }}$ values were significantly lower than $V_{\text {meso }}$ for almost AC samples. The exception was AC-L. In this case, the ratio $V_{\text {micro }} / V_{\text {total }}$ was 0.51 . It was also characterized by the highest average pore diameter, i.e., $3.02 \mathrm{~nm}$. The volume of micropores ranged from $0.31 \mathrm{~cm}^{3} / \mathrm{g}$ (AC-C) to $0.67 \mathrm{~cm}^{3} / \mathrm{g}$ (AC-L).

The IN is widely used as a quality control parameter in the production and regeneration of AC. Iodine adsorption is considered as a simple and quick test for evaluating the porous structure. Iodine has a small molecular size and it can readily penetrate deep micropores of the AC. So, the IN values gives approximate measure of the micropore content of the carbon. Based on the obtained results (Table 3), it was found that all carbons were characterized by a high iodine adsorption capacity - approx. $1300 \mathrm{mg} / \mathrm{g}$. 
These high iodine values confirm their developed porous structure and indicate a good adsorption capacity. Determining the adsorption properties should be the subject of the next stage of research. At present, it can be concluded that for all ACs, a large specific surface area and a large pore volume were found.

The prepared ACs were also tested using the thermogravimetric method in the temperature range of $35^{\circ} \mathrm{C}$ to $1200{ }^{\circ} \mathrm{C}$ (Table 4$)$.

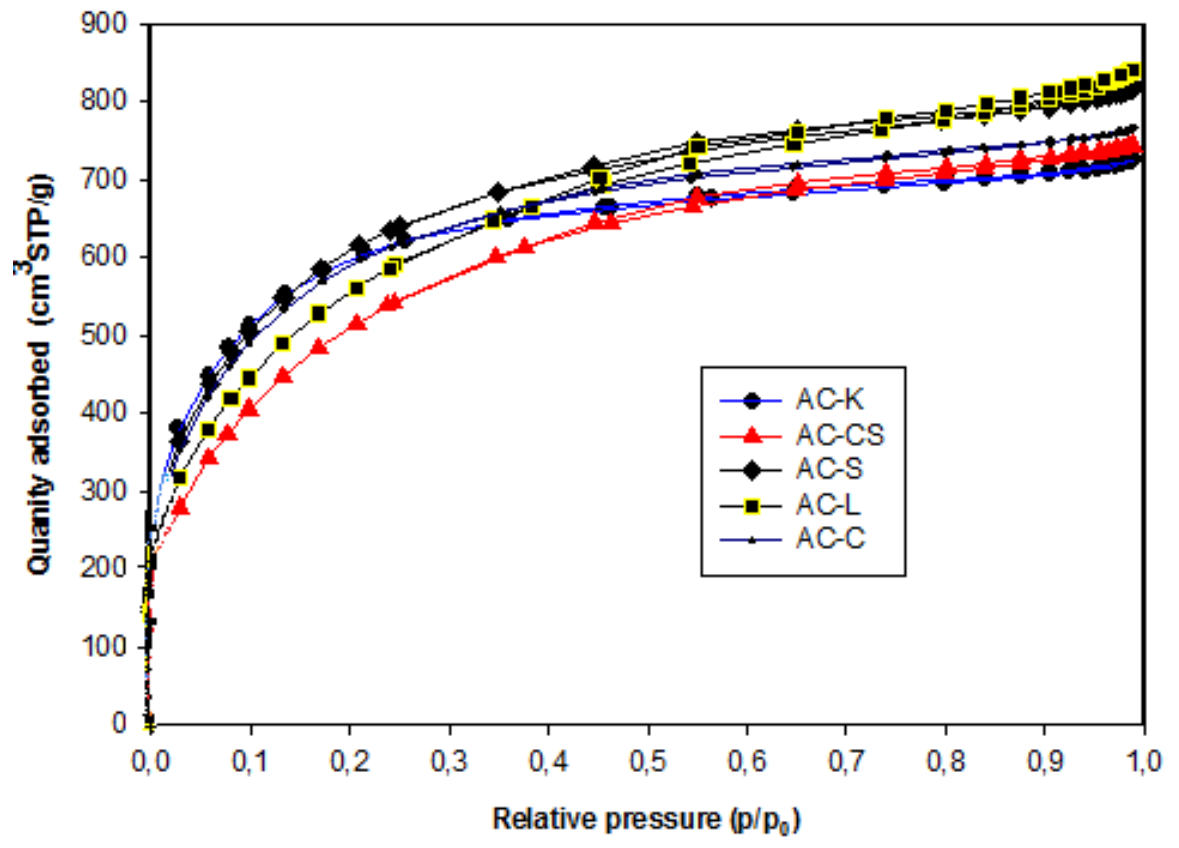

Fig. 3. $\mathrm{N}_{2}$ adsorption-desorption isotherms of activated carbon (see ACs abbreviations below Table 2)

Table 4. Thermogravimetric Analysis of ACs

\begin{tabular}{|c|c|c|c|c|c|c|}
\hline \multirow{2}{*}{ ACs } & \multicolumn{6}{|c|}{ Weight Loss (\%) } \\
\cline { 2 - 7 } & $35-200{ }^{\circ} \mathrm{C}$ & $200-500{ }^{\circ} \mathrm{C}$ & $500-700{ }^{\circ} \mathrm{C}$ & $700-900{ }^{\circ} \mathrm{C}$ & $900-1200{ }^{\circ} \mathrm{C}$ & $35-1200{ }^{\circ} \mathrm{C}$ \\
\hline AC-K & 3.17 & 5.77 & 7.71 & 7.29 & 9.20 & 33.14 \\
\hline AC-CS & 0.86 & 2.97 & 3.97 & 5.48 & 6.88 & 20.16 \\
\hline AC-S & 1.92 & 5.87 & 6.82 & 6.43 & 7.87 & 28.91 \\
\hline AC-L & 1.49 & 6.23 & 6.50 & 5.98 & 8.14 & 28.34 \\
\hline AC-C & 2.34 & 4.73 & 6.51 & 6.25 & 6.87 & 26.70 \\
\hline
\end{tabular}

Note: See ACs abbreviations below Table 2 .

During thermogravimetric tests, thermal decomposition of surface oxygen groups was observed. They exhibited different thermal stabilities because they are formed in places with different energies. The weight loss in the temperature range from $35^{\circ} \mathrm{C}$ to 200 ${ }^{\circ} \mathrm{C}$ was mainly related to the evaporation of water present in the sample, and the greatest changes in this range were recorded for AC-K. In the temperature ranges of 200 to $500{ }^{\circ} \mathrm{C}$ and 500 to $700{ }^{\circ} \mathrm{C}$, the thermal decomposition of surface acid oxygen groups occurs. Decomposition of basic oxygen groups is observed at higher temperatures (Boehm 2002). The largest loss of mass in the entire temperature range was exhibited by $\mathrm{AC}-\mathrm{K}$. On the other hand, the lowest total weight loss in the range of 35 to $1200{ }^{\circ} \mathrm{C}(20.16 \%)$, as well as in each temperature range, was recorded for AC-CS. 


\section{CONCLUSIONS}

1. Various anatomical parts of maize used in the study turned out to be good raw materials to produce activated carbon. All the obtained ACs were characterized by a rich chemical surface structure, well-developed porous structure, and sufficient thermal stability.

2. The high content of surface acid oxygen groups (approx. $2 \mathrm{mg} / \mathrm{g}$ ) in the prepared ACS were confirmed by Boehm methods and infrared spectroscopy. All ACs have an acidic surface character with the highest proportion of carboxyl groups.

3. The obtained activated carbons are characterized by a highly developed specific surface ranging from 1600 to $1965 \mathrm{~m}^{2} / \mathrm{g}$. The largest $S_{\text {BET }}$ areas were obtained by using corn kernels and stalks as precursors.

4. Activated carbons from various anatomical parts of maize are also characterized by a high proportion of mesopores in the internal capillary structure. The IN from all ACs were about $1300 \mathrm{mg} / \mathrm{g}$, which may indicate an extensive pore system and their good adsorption properties.

\section{ACKNOWLEDGMENTS}

This research was funded by statutory funds (No. 506.223.02.0) of the Poznan University of Life Sciences and the Department of Chemical Wood Technology.

\section{REFERENCES CITED}

Abd, A. A., Othman, M. R., and Kim, J. (2021). "A review on application of activated carbons for carbon dioxide capture: Present performance, preparation, and surface modification for further improvement," Environmental Science and Pollution Research 28(7), 43329-43364. DOI: 10.1007/s11356-021-15121-9

Aggarwal, P., and Dollimore, D. (1997). "The production of active carbon from corn cobs by chemical activation," Journal of Thermal Analysis 50, 525-531. DOI: 10.1007/bf01989025

ASTM D4607-94 (2006) "Standard test method for determination of iodine number of activated carbon," ASTM International, West Conshohocken, PA.

Bagheri, N., and Abedi, J. (2009). "Preparation of high surface are activated carbon from corn by chemical activation using potassium hydroxide," Chemical Engineering Research and Design 87(8), 1059-1064. DOI: 10.1016/j.cherd.2009.02.001

Bagheri, N., and Abedi, J. (2011). "Adsorption of methane on corn cobs based activated carbon," Chemical Engineering Research and Design 89(10), 2038-2043. DOI: 10.1016/j.cherd.2011.02.002

Bansal, R. C., and Goyal, M. (2005). Activated Carbon Adsorption, Taylor \& Francis Group, Boca Raton, FL, USA. DOI: 10.1201/9781420028812

Betzy, N. T., and Soney, C. G. (2015). "Production of activated carbon from natural sources," Trends in Green Chemistry 1(1), 1-5. DOI: 10.21767/2471-9889.100007

Biniak, S., Szymański, G., Siedlewski, J., and Świątkowski A. (1997). "The characterization of activated carbons with oxygen and nitrogen surface groups," 
Carbon 35(12), 1799-1810. DOI: 10.1016/S0008-6223(97)00096-1

Boehm, H. P. (1994). "Some aspects of the surface chemistry of carbon blacks and other carbons," Carbon 32(5), 759-769. DOI: 10.1016/0008-6223(94)90031-0

Boehm, H. P. (2002). "Surface oxides on carbon and their analysis: A critical assessment," Carbon 40(2), 145-149. DOI: 10.1016/S0008-6223(01)00165-8

Dąbrowski, A. (1999). "Studies in surface science and catalysis: 120 a, Adsorption and its applications in industry and environmental protection," in: Vol. I: Applications in Industry, A. Dąbrowski (ed.), Elsevier, Amsterdam

Danish, M., and Ahmad, T. (2018). "A review on utilization of wood biomass as a sustainable precursor for activated carbon production and application," Renewable and Sustainable Energy Reviews 87, 1-21. DOI: 10.1016/j.rser.2018.02.003

Doczekalska, B., Bartkowiak, M., Waliszewska, B., Orszulak, G., Cerazy-Waliszewska, J., and Pniewski, T. (2020). "Characterization of chemically activated carbons prepared from miscanthus and switchgrass biomass," Materials 13(7), 1654. DOI: 10.3390/ma13071654

Figueiredo, J. L., Pereira, M. F. R., Freitas, M. M. A., and Orfao, J. J. M. (1999). "Modification of the surface chemistry of activated carbons," Carbon 37, 1379-1389. DOI: $10.1016 / \mathrm{S} 0008-6223(98) 00333-9$

Gonzalez-Garcia, P. (2018). “Activated carbon from lignocellulosic precursors: A review of the synthesis methods, characterization techniques and applications," Renewable and Sustainable Energy Reviews 82, 1393-1414. DOI: 10.1016/j.rser.2017.04.117

Iheanacho, O. C. , Nwabanne, J. T., Chiedozie, C., Obi, C. C., and Onu C. E. (2021). "Packed bed column adsorption of phenol onto corn cob activated carbon: linear and nonlinear kinetics modeling," South African Journal of Chemical Engineering 36, 8093. DOI: 10.21203/rs.3.rs-117100/v1

Ioannidou, O. A., Zabaniotou, A. A., Stavropoulos, G. G., Islam, M. A., and Albanis, T. A. (2010). "Preparation of activated carbons from agricultural residues for pesticide adsorption," Chemosphere 80(11), 1328-1336. DOI:

10.1016/j.chemosphere.2010.06.044

Kaźmierczak, J., Nowicki, P., and Pietrzak, R. (2013). "Sorption properties of activated carbons obtained from corn cobs by chemical and physical activation," Adsorption 19(2-4), 273-281. DOI: 10.1007/s10450-012-9450-y

Kolanowski, Ł., Graś, M., Bartkowiak, M., Doczekalska, B., and Lota, G. (2020). "Electrochemical capacitors based on electrodes made of lignocellulosic waste materials," Waste and Biomass Valorization 11(7), 3863-3871. DOI: 10.1007/s12649019-00598-w

Kulp, K., and Ponte, Jr. J. G. (2000). Hand Book of Cereal Science and Technology, Marcel Dekker, Inc., New York.

Li, H., Gao, P., Cui J., Zhang, F., Wang, F., and Cheng, J. (2018). "Preparation and $\mathrm{Cr}(\mathrm{VI})$ removal performance of corncob activated carbon," Environmental Science and Pollution Research 25, 20743-20755. DOI: 10.1007/s11356-018-2026-y

Lillo-Ródenas, M. A., Cazorla-Amorós, D., and Linares-Solano, A. (2003). "Understanding chemical reaction between carbons and $\mathrm{NaOH}$ and $\mathrm{KOH}$ : An insight into the chemical activation mechanism," Carbon 41(2), 267-275. DOI: 10.1016/S0008-6223(02)00279-8

Linares-Solano, A., Lozano-Castelló, D., Lillo-Ródenas, M. A., and Cazorla-Amorós, D. (2008). "Carbon activation by alkaline hydroxides preparation and reactions, porosity and performance," in: Chemistry and Physics of Carbon, L. R. Radovic (ed.), CRC 
Press, Boca Raton. DOI: 10.1201/9781420042993

Liu, Z., Sun, Y., Xu, X., Meng, X., Qu, J., Wang, Z., Liu, C., and Qu, B. (2020).

"Preparation, characterization and application of activated carbon from corn cob by

$\mathrm{KOH}$ activation for removal of $\mathrm{Hg}(\mathrm{II})$ from aqueous solution," Bioresource

Technology 306, article no. 123154. DOI: 10.1016/j.biortech.2020.123154

Milenković, D. D., Bojić, A. L., and Veljković, V. B. (2013). "Ultrasound-assisted adsorption of 4-dodecylbenzene sulfonate from aqueous solutions by corn cob activated carbon," Ultrasonics Sonochemistry 20(3), 955-962. DOI:

10.1016/j.ultsonch.2012.10.016

Narowska, B., Kułażyński M., Łukaszewicz M., and Burchacka E. (2019). "Use of activated carbons as catalyst supports for biodiesel production," Renewable Energy 135, 176-185. DOI: 10.1016/j.renene.2018.11.006

Nethaji, S., Sivasamy, A., and Mandal, A. B. (2013). "Preparation and characterization of corn cob activated carbon coated with nano-sized magnetite particles for the removal of Cr(VI)," Bioresource Technology 134, 94-100. DOI:

10.1016/j.biortech.2013.02.012

Panwar, N., and Pawar, L. A. (2020). "Influence of activation conditions on the physicochemical properties of activated biochar: A review," Biomass Conversion and Biorefinery DOI: 10.1007/s13399-020-00870-3

Pietrzak, R., and Wachowska, H. (2003). "Low temperature oxidation of coals of different rank and different sulphur content," Fuel 8(6), 705-713. DOI: 10.1016/S0016-2361(02)00364-2

Pietrzak, R., and Bandosz, T. J. (2007). "Activated carbons modified with sewage sludge derived phase and their application in the process of $\mathrm{NO}_{2}$ removal," Carbon 45(13), 2537-2546. DOI: 10.1016/j.carbon.2007.08.030

Raymundo-Piñero, E., Azaïs, P., Cacciaguerra, T., Cazorla-Amorós, D., Linares-Solano, A., and Béguin, F. (2005). " $\mathrm{KOH}$ and $\mathrm{NaOH}$ activation mechanisms of multiwalled carbon nanotubes with different structural organization," Carbon 43(4), 786-795.

DOI: 10.1016/j.carbon.2004.11.005

Song, M., Jin, B., Xiao, R., Yang, L., Wu, Y., Zhong, Z., and Huang, Y. (2013). "The comparison of two activation techniques to prepare activated carbon from corn cob," Biomass and Bioenergy 48, 250-256. DOI: 10.1016/j.biombioe.2012.11.007

Szymański, G. S., Karpiński, Z., Biniak, S., and Świątkowski, A. (2002). "The effect of the gradual thermal decomposition of surface oxygen species on the chemical and catalytic properties of oxidized activated carbon," Carbon 40(14), 2627-2639. DOI: 10.1016/S0008-6223(02)00188-4

Tang, S., Chen, Y., Xie, R., Jiang, W., and Jiang Y. (2016). "Preparation of activated carbon from corn cob and its adsorption behavior on Cr (VI) removal," Water Science and Technology 73(11), 2654-2661. DOI: 10.2166/wst.2016.120

Tsai, W. T., Chang, C. Y., Wang, S. Y., Chang, C. F., Chien, S. F., and Sun, H. F. (2001). "Preparation of activated carbons from corn cob catalyzed by potassium salts and subsequent gasification with $\mathrm{CO}_{2}$," Bioresource Technology 78(2), 203-208. DOI: 10.1016/s0960-8524(00)00111-5

Article submitted: December 13, 2021; Peer review completed: December 19, 2021; Revised version received: January 17, 2022; Accepted: January 21, 2022; Published: January 26, 2022.

DOI: 10.15376/biores.17.1.1794-1804 